\title{
Petrophysical Parameters Estimation Using Geophysical Well Log Data of Indus Sub-Basin Area, Pakistan
}

\author{
Nasir Khan ${ }^{1}$, Pei Min Zhu ${ }^{1}$ \& Ahmed Amara Konaté ${ }^{1}$ \\ ${ }^{1}$ Institute of Geophysics and Geomatics, China University of Geosciences (Wuhan), Wuhan, Hubei, China \\ Correspondence: Nasir Khan, Institute of Geophysics and Geomatics, China University of Geosciences (Wuhan), \\ Wuhan, Hubei, China. Tel: 86-134-1955-3923. E-mail: geonasirkhan@hotmail.com
}

Received: October 16, 2013

Accepted: November 2, 2013 Online Published: November 8, 2013

doi:10.5539/jgg.v5n4p71

URL: http://dx.doi.org/10.5539/jgg.v5n4p71

\begin{abstract}
The purpose of this paper is to estimate the petrophysical parameters based on geophysical well data to identify hydrocarbon bearing zones in the Indus sub-basin's area's Sembar formation. The logging data gamma ray, spontaneous potential, resistivity, neutron and density have been utilized. The Archie's equation was used to estimate petrophysical parameters. The findings have shown five main prospective zones having good porosity and high movable hydrocarbon saturation. All the reservoir zones have low bulk density and shale volume was comprised between 4.1 to $5 \%$.
\end{abstract}

Keywords: petrophysical parameters, formation evaluation, well log, sembar formation

\section{Introduction}

The rock physics plays a crucial role in all exploration and production analysis in petroleum industry, because physical properties data constitute the basis for interpreting results. The well log data can be use for performing physical properties feasibility studies for the area of interest that can be used in all aspects of geophysical work. The petrophysical parameters estimation from well log data is an important part of the exploration and production processes in the oil and gas industries. It helps to understand the subsurface in order to recognize and estimate hydrocarbon reservoirs. The goal of this paper is aimed to estimate the petrophysical parameters from well log data in the Sembar formation. The results have shown that the petrophysical parameters estimation are important for better understanding and interpreting of geophysical data. A review of the geological background of the area is presented, focusing on the Sembar formation followed by the petrophysical parameters estimation of logs from the wells in the area

\section{Data Availability and Scale}

The well was being analyzed with vertical drilling with the use of water based mud and a bit size of 8.40 inches diameter. The data available was for the depth range of $3250 \mathrm{~m}-3480 \mathrm{~m}(230 \mathrm{~m})$ and had a composite of following logs: gamma ray, spontaneous potential, resistivity, neutron and density. The densityof resistivity of mud filtrate at surface temperature was $3.125 \mathrm{ohm}-\mathrm{m}$ and mud density was $1.92 \mathrm{gm} / \mathrm{cc}$.

In our data, the quality commonly showed a good trend however it was poor in certain regions. The borehole enlargement in these regions may be due to washout. The log scale is given in Table 1.

Table 1. The log scale

\begin{tabular}{cc}
\hline SP Log & $\mathrm{mV}$ \\
\hline GR Log & API \\
Bite Size & Inches \\
Caliper Log & Inches \\
Resistivity Log & Ohm-m \\
Neutron Porosity Log & Percentage \\
Density Log & gm/cc \\
\hline
\end{tabular}




\section{Geology Background of the Area}

Figure 1 (Kazmi \& Rana, 1982) represent the geological map and location of the area. The coordinates of the area have latitude and longitude from $25^{\circ} 0^{\prime} 0^{\prime \prime} \mathrm{N}$ to $30^{\circ} 0^{\prime} 0^{\prime \prime} \mathrm{N}$ and from $65^{\circ} 0^{\prime} 0^{\prime \prime} \mathrm{E}$ to $70^{\circ} 0^{\prime} 0^{\prime \prime} \mathrm{E}$ respectively. The stratigraphic sequence of the middle and lower Indus Basin with full details is also as shown in Figure 2 (Kadri, 1995). The area lies in the "Indus plate form and fore deep" which comprises of many structural zones. The variety of structural traps includes anticlines, thrust-faulted anticlines, and tilted fault blocks. The anticlines and thrusted anticlines occur in the foreland portions of the Indus basin as a result of compression related to the collision of the Indian and Eurasian plates (Kazmi \& Jan, 1997). Pakistan is basically comprised of two major sedimentary basins namely the Indus basin and Balochistan basin (which is west of the Axial Belt). The Indus basin is basically from the Khairabad-Panjal thrust to the Ornach-Nal \& Quetta fault system that runs along the western margin of the axial belt. The Kohat-Potwar, Sulaiman, Kirthar and the axial belt are different geological provinces of the Indus basin. The axial belt evolved on the NW margin of the Indian plate (Siddiqui, 2009). The total area covered by Indus basin is about $533,500 \mathrm{~km}^{2}$ which contains more than $15,000 \mathrm{~m}$ of thick sediments ranging in age from the Precambrian to recent times. The Indus basin is sub classified into three main basins namely, the Upper Indus basin, the Middle Indus basin, and the Lower Indus basin. The Jacobabad-Khairpur, Sukkur rift zone and Sargodha divide the Indus basin into these three sub basins. Our current study belongs to the well data from Middle and Lower Indus sub-basin having the source and reservoir in Sembar formation. The area of the Middle and Lower Indus sub-basins is bounded by the Pizu-uplift to the north and the offshore Indus basin to the south and the Ornach-Chaman fault systems to the west.
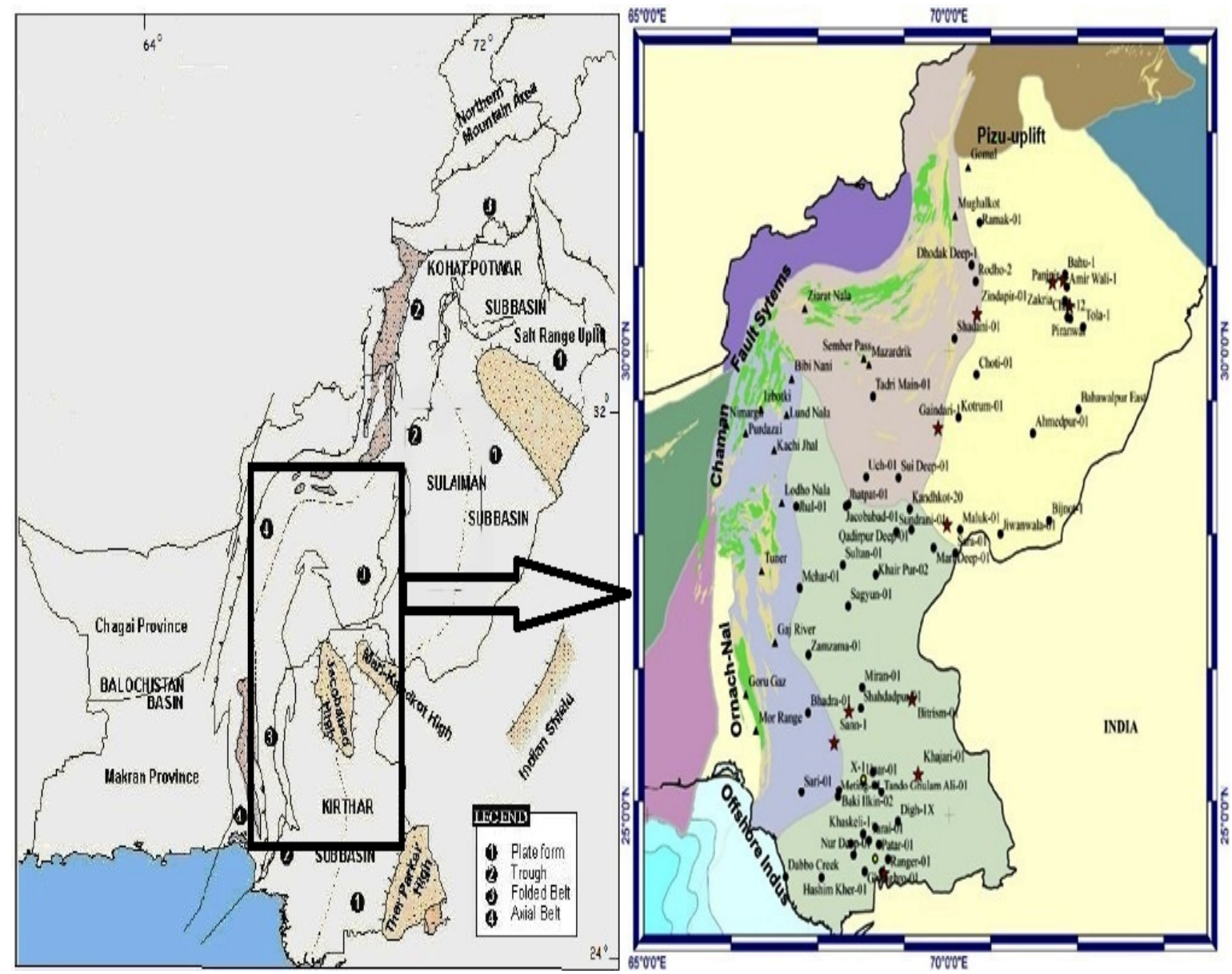

Figure 1. Map showing location and geology of the middle and lower Indus Basin (after Kazmi \& Rana, 1982) 


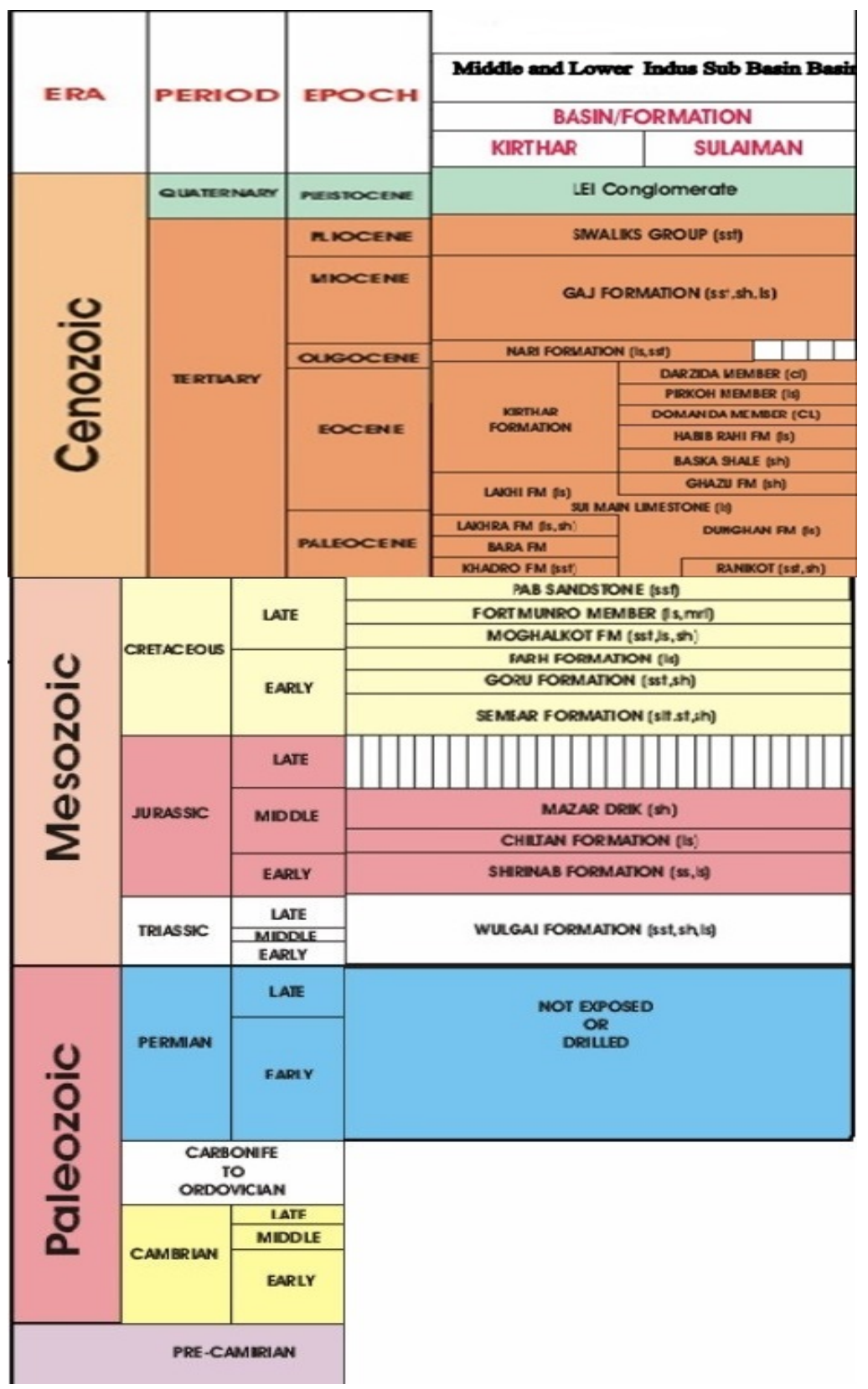

Figure 2. Stratigraphic sequence of the Middle and Lower Indus basin Area (after Kadri, 1995)

The Sembar Formation is of the cretaceous period (Williams, 1959) and mostly deposited as marine environments in the Lower and Middle Indus basin. Its thickness varies from 0 to more than $260 \mathrm{~m}$. Its sequence consists of black shale with subordinate amounts of siltstone, sandstone, and nodular argillaceous limestone. The shale and siltstone are commonly glauconitic. As shown in figure 3 (Ahmed et al., 2012), the Goru formation is overlying the Sembar formation which is composed of sandstone, siltstone, shale, limestone, and conglomerate. The type locality of the Sembar formation is the Sembar Pass area, where it is $133 \mathrm{~m}$ thick (Iqbal \& Shah, 1980; Shah, 2009). The analysis of potential source rocks and produced oil and gas of the area have demonstrated that the Sembar formation is the most likely source of oil and gas for most of the producing fields in the Indus basin and has been identified as the primary source (Quadri \& Shuaib, 1986). The most found fossils in the Sembar formation from the Neocomian period and these fossils are from the Late Jurassic (Fatmi, 1977) period. The subsurface depth ranges of the Sembar formation ranges from less than $1000 \mathrm{~m}$ to more than 5000 . There have been a number of number unpublished which have researched the depositional frame work and reservoir stratigraphy of the Sembar formation in this area (Milan \& Rodgers, 1993; IEDS, 1995; Krois et al., 1998). 


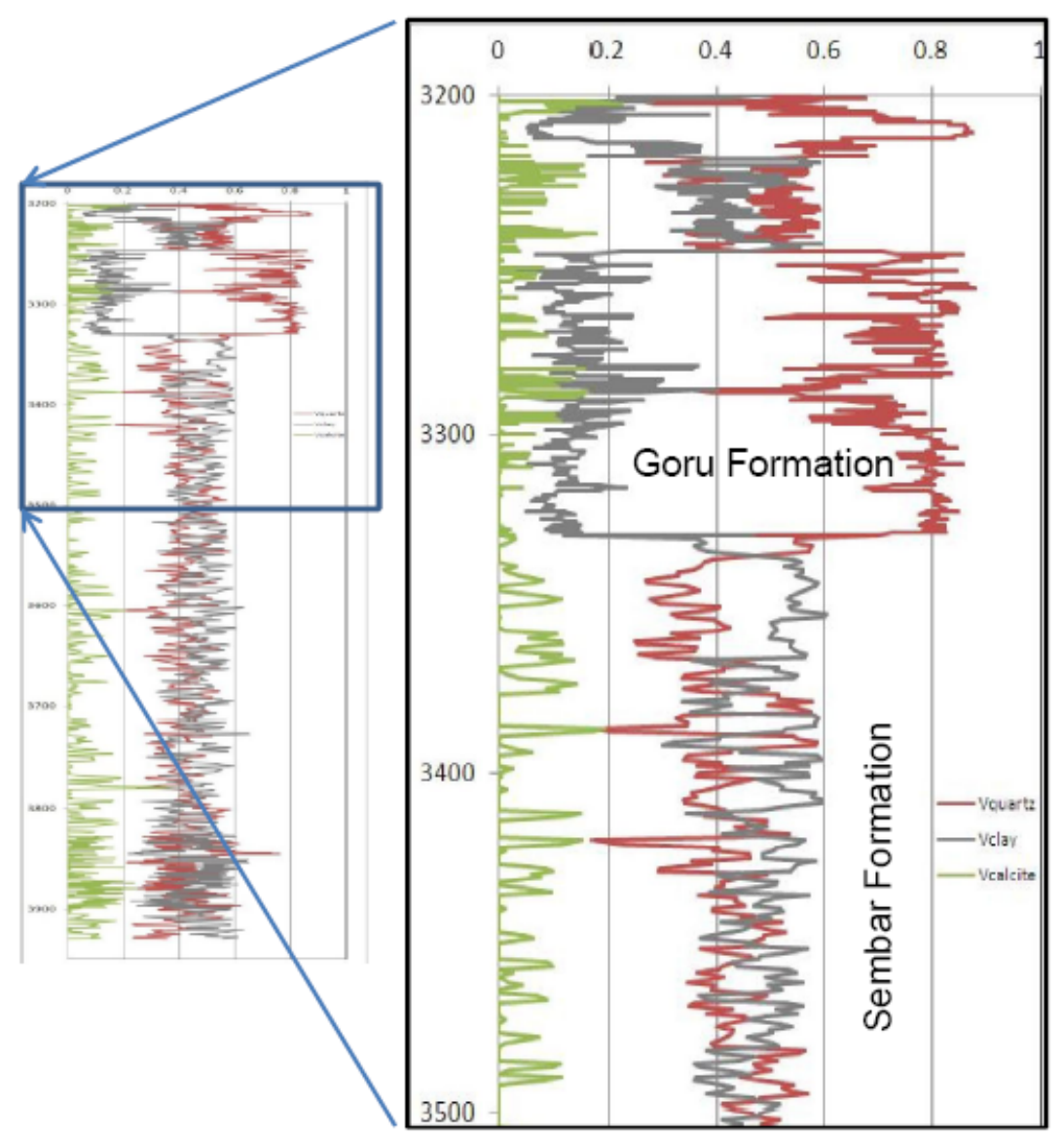

Figure 3. Represent goru formation (after Ahmed et al., 2012)

\section{Methodology}

We have done the formation evaluations with the help of petrophysical parameters for Sembar formation of the Middle and Lower Indus basin area, the petrophysical parameters are estimated by the methodology as described by Doveton (1999), Hearst et al. (2000), Darling (2005).

\section{Step 1:}

We have selected a 'zone of interest 'which is identified from a hydrocarbon accumulation stand point by integrating log responses of different geophysical tools. The characteristic log responses usually indicate the possibility of the presence of hydrocarbons such as high resistivity value, low gamma ray value, negative deflection of SP log, etc. The zones of interests are selected by looking at the mud-cake formation and resistivity $\log$. Here we have not considered for petrophysical analysis the zones which do not satisfy all the characteristic log response for hydrocarbon bearing zones. We have selected five hydrocarbon bearing zones for petrophysical analysis as shown in the Table 2 .

Table 2. The zones of interest

\begin{tabular}{ccc}
\hline Zones & Depth Range $(\mathrm{m})$ & Thickness $(\mathrm{m})$ \\
\hline 1 & $3250-3266$ & 16 \\
2 & $3298-3315$ & 17 \\
3 & $3360-3378$ & 18 \\
4 & $3410-3429$ & 19 \\
5 & $3460-3480$ & 20 \\
\hline
\end{tabular}


Step 2:

The calculation of formation temperature was done by the formula

$$
\mathrm{T} 2=\mathrm{T} 1+\text { Geothermal Gradient } \times \mathrm{D}
$$

Where $\mathrm{T} 2$ is the formation temperature of the zone of interest, and $\mathrm{T} 1$ is the mean surface temperature and $\mathrm{D}$ is the depth of the particular zone. The full well had been logged at one run and the surface temperature was $30{ }^{\circ} \mathrm{C}$ and the geothermal gradient of the area is varying from $16-22{ }^{\circ} \mathrm{C} / \mathrm{km}$ but the most common value was $18^{\circ} \mathrm{C} / \mathrm{km}$. So for purpose of petrophysical analysis $18^{\circ} \mathrm{C} / \mathrm{km}$ has been taken. Table 3 represents the surface temperature of zones and Table 4 shows the formation's temperature respectively.

Table 3. Surface temperature of zones

\begin{tabular}{ccc}
\hline Zone & Surface Temperature ${ }^{\circ} \mathrm{C}$ & Surface Temperature ${ }^{\circ} \mathrm{F}$ \\
\hline 1 & 30 & 86 \\
2 & 30 & 86 \\
3 & 30 & 86 \\
4 & 30 & 86 \\
5 & 30 & 86 \\
\hline
\end{tabular}

Table 4. The formation's temperature

\begin{tabular}{cccc}
\hline Zones & Formation Depth $(\mathrm{m})$ & Formation Temperature ${ }^{\circ} \mathrm{F}$ & Formation Temperature ${ }^{\circ} \mathrm{C}$ \\
\hline 1 & 3250 & 191.3 & 88.5 \\
2 & 3298 & 192.8 & 89.3 \\
3 & 3360 & 194.8 & 90.48 \\
4 & 3410 & 196.4 & 91.38 \\
5 & 3460 & 198.1 & 92.28 \\
\hline
\end{tabular}

Step 3:

We have calculated the resistivity of mud filtrate at formation temperature (Rmf), we have read Rmf from the header file at surface temperature. Then we have determined the $\mathrm{Rmf}$ at formation temperature which is as given below in Table 5 using the following formula.

$$
\begin{aligned}
& R_{m_{2}}=R_{m_{1}} \frac{\left[T_{1}+6.77\right]}{\left[T_{2}+6.77\right]} \\
& R_{m_{2}}=R_{m 1} \frac{\left[T_{1}+21.5\right]}{\left[T_{2}+21.5\right]}
\end{aligned}
$$

Where $R_{m_{1}}$ is temperature in ${ }^{\circ} \mathrm{F}$, and $R_{m_{2}}$ is temperature in ${ }^{\circ} \mathrm{C}$. T2 is the formation temperature and $\mathrm{T} 1$ is the mean surface temperature, and $R_{m_{1}}$ and $R_{m_{2}}$ are the resistivity of mud filtrate at surface temperature and the resistivity of mud filtrate at formation temperature respectively.

Table 5. The resistivity of mud filtrate at formation temperature of zones

\begin{tabular}{ccc}
\hline $\mathrm{Rm}_{2}\left({ }^{\circ} \mathrm{C}\right)$ & $\mathrm{Rm}_{2}\left({ }^{\circ} \mathrm{F}\right)$ & Zones \\
\hline 0.468 & 0.464 & Zone 1 \\
0.464 & 0.460 & Zone 2 \\
0.4599 & 0.456 & Zone 3 \\
0.456 & 0.452 & Zone 4 \\
0.4526 & 0.449 & Zone 5 \\
\hline
\end{tabular}


Step 4:

Then we have calculated the formation water resistivity $\left(R_{w_{e}}\right)$ from SP log by the reading value of SP deflection from log as well as the $R_{m f}$ at formation temperature then we convert the $R_{m f}$ at formation temperature to $R_{m f e}$

$$
R_{w e}=R_{m f e} * 10^{\left(\frac{S S P}{61+0.133 T_{f}}\right)}
$$

Where SSP is the reading value of SP deflect and Rmfe is obtained by converting Rmf values of using the schlumberger standard graph.

The calculation for the zonal parameters and the calculation for formation water resistivity $\left(R_{w}\right)$ used for petrophysical analysis are given in Table 6 and Table 7 respectively.

Table 6. The zonal parameters

\begin{tabular}{ccccccccc}
\hline Zone & $\begin{array}{c}R_{f} \\
(\Omega \mathrm{m})\end{array}$ & $\begin{array}{c}\text { GR max } \\
(\mathrm{API})\end{array}$ & $\begin{array}{c}\text { GRmin } \\
(\mathrm{API})\end{array}$ & $\begin{array}{c}\text { GRlog } \\
(\mathrm{API})\end{array}$ & $\begin{array}{c}\text { Mud } \\
\text { Density } \\
\rho \mathrm{\rho f}(\mathrm{gm} / \mathrm{cc})\end{array}$ & $\mathrm{a}$ & $\mathrm{m}$ & $\mathrm{n}$ \\
\hline 1 & 1.298 & 150.0 & 22.5 & 40 & 1.92 & 0.62 & 2.15 & 2 \\
2 & 1.294 & 138.2 & 24.1 & 38 & 1.92 & 0.62 & 2.15 & 2 \\
3 & 1.285 & 136.3 & 23.5 & 36.6 & 1.92 & 0.62 & 2.15 & 2 \\
4 & 1.274 & 134.7 & 21.4 & 34.8 & 1.92 & 0.62 & 2.15 & 2 \\
5 & 1.267 & 130.1 & 20.2 & 32.9 & 1.92 & 0.62 & 2.15 & 2 \\
\hline
\end{tabular}

Table 7. The formation resistivity calculations

\begin{tabular}{cccccccc}
\hline Zone & $\mathrm{F}\left({ }^{\circ} \mathrm{H}\right)$ & $\begin{array}{c}R_{m f} \\
(\Omega \mathrm{m})\end{array}$ & $\mathrm{SSP}$ & $R_{f}(\Omega \mathrm{m})$ & $\begin{array}{c}R_{m f e} \\
(\Omega \mathrm{m})\end{array}$ & $\begin{array}{c}R_{w e} \\
(\Omega \mathrm{m})\end{array}$ & $\begin{array}{c}R_{w} \\
(\Omega \mathrm{m})\end{array}$ \\
\hline 1 & 191.3 & 0.464 & -69 & 1.298 & 0.394 & 0.040 & 0.05 \\
2 & 192.8 & 0.460 & -66 & 1.294 & 0.391 & 0.067 & 0.09 \\
3 & 194.8 & 0.456 & -64 & 1.285 & 0.387 & 0.071 & 0.07 \\
4 & 196.4 & 0.452 & -50 & 1.274 & 0.384 & 0.102 & 0.12 \\
5 & 198.1 & 0.449 & -43 & 1.267 & 0.381 & 0.123 & 0.9 \\
\hline
\end{tabular}

Step 5:

The next step is the calculation of Shale Volume $\left(V_{s h}\right)$ which is present in the zone of interest and was determined by the GR log. Vsh from the GR log can be calculated by following formula

$$
I_{G R}=\frac{(G R \log -G R \min )}{(G R \max -G R \min )}
$$

Table 8. Represents the shale volume calculation

\begin{tabular}{ccccc}
\hline Zone & $I_{G R}$ & Clavier & steibel & V shale(accepted) \\
\hline 1 & 0.137 & 0.063 & 0.050 & 0.050 \\
2 & 0.121 & 0.064 & 0.043 & 0.043 \\
3 & 0.116 & 0.052 & 0.041 & 0.041 \\
4 & 0.118 & 0.053 & 0.042 & 0.042 \\
5 & 0.115 & 0.052 & 0.041 & 0.041 \\
\hline
\end{tabular}


The Gamma Ray Index $\left(I_{G R}\right)$ and Shale Volume $\left(V_{s h}\right)$ relation becomes non-linear for both structured clays and dispersed clays. The wide varities of non-linear relationships exist between IGR and Vsh but none is universally accepted. A summary of this non-linear relationship is illustrated below.

$$
\begin{gathered}
\text { Linear }=I_{G R} \\
\text { Clavier }\left(V_{s h}\right) 1.7-\left[3.38-\left(I_{G R}+0.7\right) 2\right] 1 / 2 \\
\left(\text { Steiber } V_{s h}\right) \quad V_{s h}=\frac{I_{G R}}{3-2 \times I_{G R}}
\end{gathered}
$$

Step 6:

The Determination of Neutron Porosity and Density Porosity is done as Effective porosity $(\Phi e)$ is calculated firstly by combining neutron porosity and density porosity. The neutron porosity can be read directly from log and the density porosity needs to be calculated from density log using the formula as below.

$$
\Phi_{D}=\frac{\left(\rho_{m a}-\rho_{b}\right)}{\left(\rho_{m a}-\rho_{f}\right)}
$$

where

$\rho m a=$ density of the matrix of the formation and in Sembar formation its range is from $(2.62-2.91) \mathrm{gr} / \mathrm{cc} \rho \mathrm{f}=$ density of the formation fluid in the vicinity of borehole and here its range from mud filtrate is $(0.6-1.1) \mathrm{gr} / \mathrm{cc} \rho \mathrm{b}=$ bulk density of the Sembar formation here $2.10 \mathrm{gr} / \mathrm{cc}$.

Step 7:

The next step is the correction of neutron porosity and density porosity for the presence of shale is done as neutron porosity which is read from the log and density porosity which is calculated need to be corrected for volume of shale present in the formation as follows.

1. Corrected neutron porosity.

$$
\Phi_{N C}=\Phi_{N}-V_{S h} \Phi N_{S h}
$$

2. Corrected density porosity.

$$
\Phi_{D C}=\Phi_{D}-V_{S h} \Phi N_{D s h}
$$

Step 8:

For presence of shale volume we have then done the calculation of effective porosity (Фe) which is calculated and given by table 9 by combining corrected neutron and density porosities using the following formula.

$$
\phi \mathrm{e}=\sqrt{\frac{\left(\Phi_{N C}^{2}+\Phi_{D C}^{2}\right.}{2}}
$$

Table 9 . The porosity calculations

\begin{tabular}{cccccccc}
\hline Zones & $\begin{array}{c}\text { Volume } \\
\text { Shale }\left(V_{\text {sh }}\right)\end{array}$ & $\rho_{b}$ & $\Phi_{D}$ & $\Phi_{N}$ & $\Phi_{D C}$ & $\Phi_{N C}$ & $\Phi_{\text {Effective }}$ \\
\hline 1 & 0.050 & 2.10 & 0.402 & 0.19 & 0.393 & 0.184 & 0.306 \\
2 & 0.043 & 2.01 & 0.305 & 0.15 & 0.298 & 0.085 & 0.219 \\
3 & 0.041 & 2.16 & 0.274 & 0.09 & 0.266 & 0.028 & 0.189 \\
4 & 0.042 & 2.08 & 0.311 & 0.096 & 0.303 & 0.033 & 0.215 \\
5 & 0.041 & 2.17 & 0.296 & 0.15 & 0.288 & 0.0885 & 0.213 \\
\hline
\end{tabular}


Step 9:

We have then determined the formation factor (F) using the formula.

$$
F=a / \Phi_{m}
$$

Where, $\mathrm{a}=$ tortuosity factor, $\mathrm{m}=$ cementation factor;

And both have constant having values, $\mathrm{a}=0.62, \mathrm{~m}=2.1$.

Step 10

We then computed the water saturation ( $\mathrm{Sw})$ using "Archie's Equation"

$$
S_{w}^{n}=\frac{\left(F * R_{w}\right)}{R_{t}}
$$

where

$\mathrm{Sw}=$ water saturation;

$\mathrm{N}=$ saturation exponent (usually taken as 2);

$\mathrm{Rt}=$ true resistivity, as read from the deep resistivity log;

$\mathrm{F}=$ formation factor.

The Table 10 and Table 11 show the saturation calculations of the area.

Table 10. The saturation calculations

\begin{tabular}{cccccccc}
\hline zone & Depth & $\Phi_{\text {Effective }}$ & $\mathrm{F}$ & $R_{w}$ & $R_{t}$ & $S_{w} \%$ & $S_{h c \%}$ \\
\hline 1 & $3250-3266$ & 0.306 & 7.908 & 0.05 & 70 & 7.51 & 92.5 \\
2 & $3298-3315$ & 0.219 & 16.234 & 0.09 & 150 & 9.87 & 90.13 \\
3 & $3360-3378$ & 0.189 & 22.284 & 0.07 & 225 & 8.326 & 91.7 \\
4 & $3410-3429$ & 0.215 & 16.890 & 0.12 & 210 & 9.82 & 90.18 \\
5 & $3460-3480$ & 0.213 & 17.233 & 0.9 & 190 & 28.57 & 71.43 \\
\hline
\end{tabular}

Table 11. Showing the saturation calculations

\begin{tabular}{cccccc}
\hline Zone & $S_{w}$ & $S_{h c}$ & $R_{f}(\Omega \mathrm{m})$ & $R_{x_{0}}$ & $S_{x_{0}}$ \\
\hline 1 & 0.0751 & 0.925 & 1.298 & 10 & 0.605 \\
2 & 0.0987 & 0.9013 & 1.294 & 20 & 0.611 \\
3 & 0.083 & 0.917 & 1.285 & 20 & 0.712 \\
4 & 0.098 & 0.9018 & 1.274 & 25 & 0.552 \\
5 & 0.285 & 0.7143 & 1.267 & 20 & 0.621 \\
\hline
\end{tabular}

Step 11:

After computing the water saturation $\left(S_{w}\right)$ we determined the hydrocarbon saturation $\left(S_{h c}\right)$ from the relation.

$$
S_{h c}=1-S_{W}
$$

where,

$S_{h c}=$ oil saturation of the zone of interest.

Step 12:

We then estimated the movable hydrocarbon as water saturation in the flushed zone $\left(S_{x_{0}}\right)$. 


$$
S x_{0}=\sqrt{\frac{\left(F^{*} R_{m f}\right)}{R_{x_{0}}}}
$$

Where $R_{x_{0}}=$ resistivity of the flushed zone given by Micro-logs and $\left(1-S_{x_{0}}\right)$ gives the hydrocarbon present within the flushed zone i.e. immovable hydrocarbon. which enables us calculating 'movable hydrocarbon' by subtracting the residual hydrocarbon. $\left(1-S_{x_{0}}\right)$ from total hydrocarbon saturation.

$$
S_{h c}=S_{x_{0}}-S_{w}
$$

Table 12 represents the Movable-immovable hydrocarbon out of total pore fluids calculations.

Table 12. The movable-immovable hydrocarbon out of total pore fluids calculations

\begin{tabular}{cccccc}
\hline Zone & $S_{w}$ & $S_{h c}$ & $S_{x_{0}}$ & $S_{h c i m}=\left(1-S_{x_{0}}\right)$ & $S_{h c m}$ \\
\hline 1 & .0751 & 92.5 & 0.605 & 0.395 & 0.529 \\
2 & 0.0987 & 90.13 & 0.611 & 0.389 & 0.458 \\
3 & 0.083 & 91.7 & 0.712 & 0.288 & 0.629 \\
4 & 0.098 & 90.18 & 0.552 & 0.448 & 0.454 \\
5 & 0.285 & 71.43 & 0.621 & 0.379 & 0.336 \\
\hline
\end{tabular}

\section{Results}

We have analyzed the five zone of interest for hydrocarbon accumulation and found good results. These zones have shown prospective for hydrocarbon accumulation and have good porosity. Figure 4 represents the pie chart showing the relationship between $S_{w}, S_{w} \& S_{\text {hcim }}$ together. 


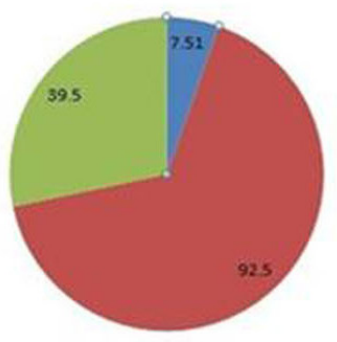

Zone 1
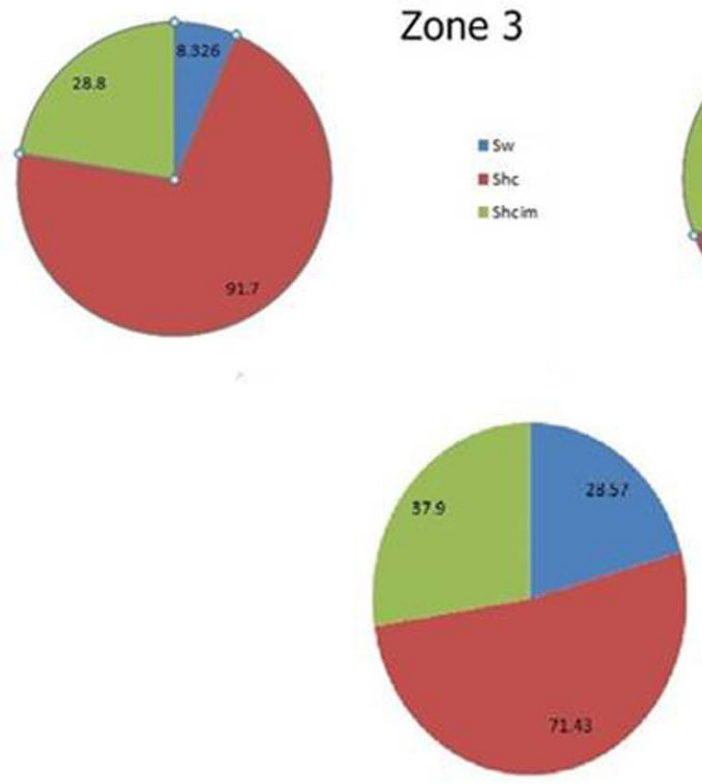
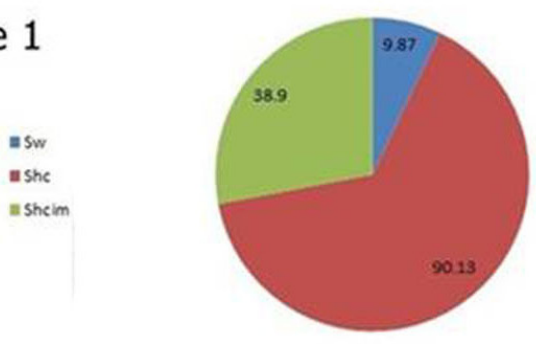

Zone 2

Zone 3

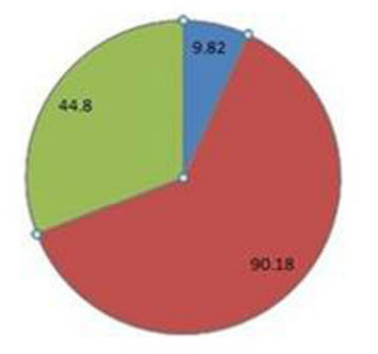

Zone 4

Zone 5 nsw

ashe

sshcim

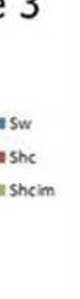

wswe

sheim

Figure 4. The results(In Percentages) of $S_{w}, S_{h c} \& S_{h c i m}$

The detailed results for these zones are given below.

Zone1: Depth (3250-3266) $m$

The Thickness of this zone is $16 \mathrm{~m}$, the gamma value for this zone is 40.0 API, which is relatively low, the shale volume in this zone is $5 \%$. The low value of $R_{x_{0}}$ and high value of $R_{t_{0}}$ against the formation indicate a good amount of moveable hydrocarbon. The effective porosity in this zone is $30.6 \%$ which is good. The true resistivity in this zone is $70 \mathrm{ohm}-\mathrm{m}$ which is the lowest value in all five zones. The hydrocarbon saturation in this zone is $92.5 \%$ which is very good.

Zone 2: Depth (3298-3315) $m$

The thickness of this zone is $17 \mathrm{~m}$, the gamma value for this zone is $38.0 \mathrm{API}$, which is relatively low, the shale volume in this zone is $4.3 \%$. The effective porosity in this zone is $21.9 \%$, which is quite good. The hydrocarbon saturation in this zone is $90.13 \%$, which is very good. The true resistivity in this zone is $150 \mathrm{ohm}-\mathrm{m}$, which is relatively low.

Zone 3: Depth (3360-3378) $m$

The thickness of this zone is $18 \mathrm{~m}$, the gamma value for this zone is 36.6 API, which is relatively low, the shale volume in this zone is $4.1 \%$, the effective porosity in this zone is $18.9 \%$, which is relatively low. The true resistivity in this zone is $225 \mathrm{ohm}-\mathrm{m}$, which is the highest resistivity in all the five zones. The hydrocarbon saturation in this zone is $91.7 \%$, which is very good.

Zone 4: Depth (3410-34298 m) 
The thickness of this zone is $19 \mathrm{~m}$, the gamma value for this zone is 34.8 API, which is relatively low, and the shale volume in this zone is $4.2 \%$. The effective porosity in this zone is $21.5 \%$, which is good. The true resistivity in this zone is $210 \mathrm{ohm}-\mathrm{m}$, which is high. The hydrocarbon saturation in this zone is $90.18 \%$, which is very good.

Zone 5: Depth (3460-3480) $\mathrm{m}$

The thickness of this zone is $20 \mathrm{~m}$, the gamma value for this zone is 32.9 API, which is relatively low, and the shale volume in this zone is $4.1 \%$. The effective porosity in this zone is $21.3 \%$, which is quite good. The True resistivity in this zone is $190 \mathrm{ohm}-\mathrm{m}$, which is high. The hydrocarbon saturation in this zone is $71.43 \%$, which is quite good.

\section{Conclusions}

The petrophysical parameters estimation has been developed and proven:

1) There are five hydrocarbon bearing zones having thickness varying from $16 \mathrm{~m}$ to $20 \mathrm{~m}$.

2) The shale volume varies from $4.1 \%$ to $5 \%$.

3) The effective porosity of the zones varies from $18.9 \%$ to $30.6 \%$.

4) The water saturation varies from $7.51 \%$ to $28.57 \%$.

5) The hydrocarbon saturation varies from $71.43 \%$ to $93.5 .6 \%$.

6) The movable hydrocarbon saturation varies from $33.6 \%$ to $62.9 \%$.

7) These zones are gas zone which is indicated by the low bulk density.

These results can be used in the estimation and prediction of resources, reserves and performance.

\section{References}

Doveton, H. (1999). Basic Oil and Gas Log Analysis (pp. 8-16). Kansas Geological Survey, USA.

Fatmi, A. N. (1977). Mesozoic in shah. In S. M. I (Ed.), Staratigraphy of Pakistan, GSP, Memoirs, 12.

I. E. D. S. (1995). A sequence stratigraphic study of the Lower Goru - Sembar Formations of Lower and Middle Indus Basins of Pakistan and Rajasthan. Multiclient study.

Iqbal, M. W. A., \& Shah, S. M. I. (1980). A guide to the stratigraphy of Pakistan. Geol. Surv. Pak. Quetta, 531-534.

Joseph, R. H., Philip, H. N., \& Paillet, F. L. (2000). Well logging for physical properties. John Wiley \& Sons USA

Kadri, I. B. (1995). Petroleum Geology of Pakistan (p. 275). Published by Pakistan Petroleum Limited, Ferozsons (pvt) limited.

Kazmi, A. H., \& Jan, M. Q. (1997). Geology and tectonics of Pakistan. In A. H, Kazmi \& R. A, Rana (Eds), Tectonics map of Pakistan. Pakistan: Geol Surv.

Krois, P., Mahmood, T., \& Milan, G. (1998). Miano Field: A case history of model driven exploration: Pakistan. Petroleum Convention 98, Islamabad, Pakistan.

Milan, G., \& Rodgers, M. (1993). Stratigraphic evolution and play possibilities in the Middle Indus Area. Pakistan: Presented at SPE Pakistan Seminar, Islamabad.

Ahmed, N., Mateen, J., Shehzad, K., Mehmood, N., \& Fahad, A. (2012). Shale Gas Potential of Lower Cretaceous Sembar Formation in Middle and Lower Indus Sub-Basins, Pakistan. Oral presentation at PAPG/SPE Annual Technical Conference 2011, Islamabad, Pakistan

Quadri, V. U. N., \& Shuaib, S. M. (1986). Hydrocarbon prospects of southern Indus basin, Pakistan. Am. Assoc. Pet. Geol., Bull.;(United States), 70(6).

Shah, S. I. (2009). Stratigraphy of Pakistan. Government of Pakistan Ministry of Petroleum \& Natural Resorces Geological Survey of Pakistan.

Siddiqui, N. K. (2009). Sedimentary basin architecture of Pakistan and Summarized stratigraphy of Pakistan in Proterozoic and Phanerozoic integrated stratigraphy (South-East Asia). India, Pakistan, Bangladesh, Myanmar and Sri Lanka: ONGC Bulletin, 44, 2.

Darling, T. (2005). Well Logging and Formation Evaluation. Elsevier Publisher.

Williams, M. D. (1959, May). 19. Stratigraphy of the Lower Indus Basin, West Pakistan. In 5th World Petroleum Congress. 


\section{Copyrights}

Copyright for this article is retained by the author(s), with first publication rights granted to the journal.

This is an open-access article distributed under the terms and conditions of the Creative Commons Attribution license (http://creativecommons.org/licenses/by/3.0/). 